\title{
Douglas W. McKee (1930-2021)
}

Isabel Fonseca

blo@fct.unl.pt

Foi com profundo pesar que recebemos a notícia do falecimento do Dr. Douglas W. McKee no passado dia 24 de setembro.

O Dr. McKee nasceu em Toronto (Canadá), mas foi educado em Londres (Reino Unido), tendo obtido o grau de Doutor (PhD) no Queen Mary College da Universidade de Londres, na especialidade de Química Física, em 1954. Realizou um pós-doutoramento no National Research Council (Ottawa, Canadá). Em 1982, foi-Ihe conferido o maior grau académico da Universidade de Londres (Doctor of Science).

Durante 33 anos teve uma carreira brilhante como cientista no Departamento de Investigação e Desenvolvimento da General Electric, tendo publicado cerca de 150 artigos e patentes. Posteriormente, foi Professor Convidado na Universidade de Haute Alsace (1994) e no Departamento de Química (Grupo de Catálise Heterogénea) da Faculdade de Ciências e Tecnologia da Universidade Nova de Lisboa (1995).

$23^{r d}$ Biennial Carbon Conference, The Pennsylvania State University, University Park, PA (14-18 de julho de 1997).

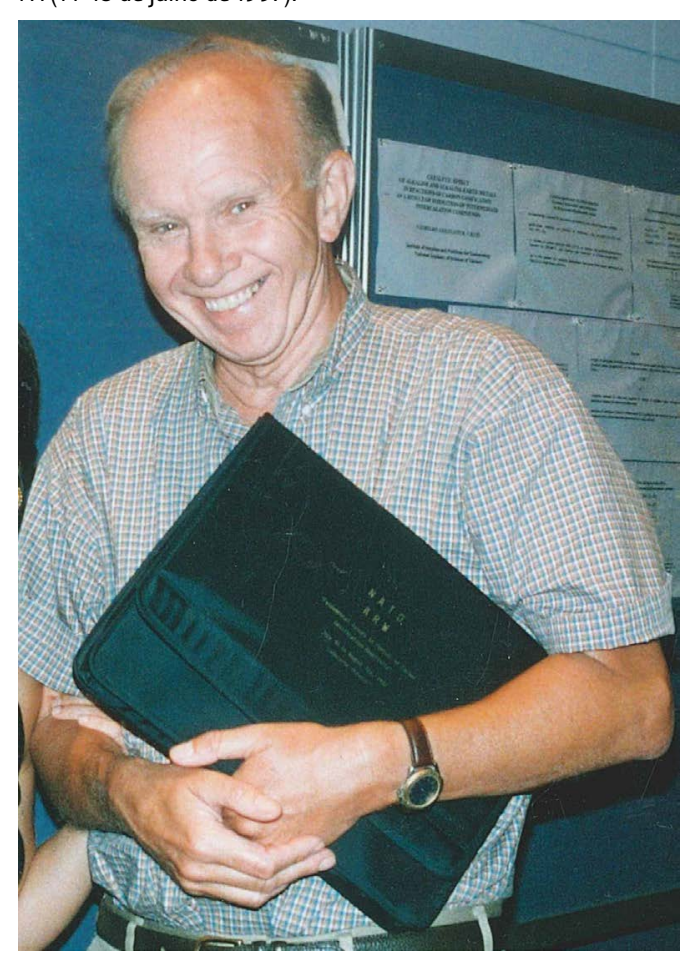

Foi membro da Royal Society of Chemistry, American Chemical Society e Materials Research Society. Durante 10 anos foi Presidente da Comissão Executiva da American Carbon Society. Foi Editor Associado da revista Carbon (Elsevier), durante vários anos. Em 1987, recebeu o prémio Graffin Travelling Lectureship da American Carbon Society pela sua importante contribuição para a Ciência e Engenharia.

O Doutor McKee é bem conhecido dos colegas que desenvolvem a sua investigação na área dos materiais de carbono, e as suas publicações sobre oxidação e gasificação catalítica de carbono e grafite são referências incontornáveis no tema. A sua disponibilidade para colaborar com os grupos portugueses (nomeadamente - Laboratório de Catálise e Materiais, LCM/FEUP, e - Grupo de Catálise Heterogénea da F(T/UNL) foi determinante para a sua consolidação. Destaca-se, em particular, a sua estadia como Professor Visitante na UNL em 1995, pois esta foi a sua última afiliação científica, tendo originado a publicação de três artigos:

- I. F. Silva, D. W. McKee, L. S. Lobo, A kinetic and in situ XRD study of carbon reactions catalysed by nickel, cobalt, molybdenum and their mixtures, J. Catal. 1997, 170, 54-61. DOI: 10.1006/jcat.1997.1723.

- A. M. Ramos, I. F. Silva, J. Vital, D. W. McKee, Polymerization of pinenes and styrene using activated carbons as catalysts and supports for metal catalysts, Carbon 1997, 35, 1187-1189. DOI: 10.1016/S0008-6223(97)84649-0.

- Sónia A. Carabineiro, Douglas W. McKee, Isabel F. Silva, Uncatalysed and catalysed $\mathrm{CO}_{2}$ reaction using metal catalysts and binary vanadium mixtures supported on activated carbon, Carbon 2001, 39, 451-463. DOI: 10.1016/S0008-6223(00)00151-2. Durante a sua permanência no grupo de Catálise Heterógena, foi uma honra termos trabalhado sob a sua orientação. Sendo um cientista internacionalmente reconhecido na área da química superficial dos materiais de carbono, e da sua utilização como catalisadores, foi muito importante o seu contributo para a nossa formação.

Foi um privilégio ter trabalhado com um ser humano tão generoso, paciente e gentil.

Muito Obrigada, Prof. McKee, pela sua Amizade e Carinho.

Eterna Gratidão. 